\title{
Utilização do resíduo da extração de esmeraldas em uma formulação de massa de revestimento cerâmico
}

\author{
(Use of the extraction residue of emeralds in a \\ formulation mass of ceramic tiles)
}

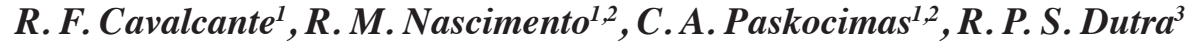 \\ ${ }^{l}$ Programa de Pós-Graduação em Engenharia Mecânica - PPgEM - UFRN \\ ${ }^{2}$ Departamento de Engenharia Materiais - DEMAT - UFRN \\ ${ }^{3}$ Departamento de Engenharia Materiais - DEMAT - UFPB \\ Universidade Federal do Rio Grande do Norte - UFRN, Av. Salgado Filho 2860, Lagoa Nova, \\ Natal, RN Brasil, 59075-900 \\ ronaldofcavalcante@gmail.com,rmaribondo@ufrnet.br, \\ paskocimas_ca@hotmail.com,ricardodutra@ct.ufpb.br
}

\begin{abstract}
Resumo
Empresas envolvidas na mineração de esmeralda e beneficiamento representam uma importante área de desenvolvimento industrial no Brasil, com significativa contribuição para a produção mundial desse minério. Como resultado, grandes volumes de resíduos de esmeralda são constantemente gerados e abandonados no ambiente, contribuindo negativamente para a sua preservação. Por outro lado o interesse no uso do resíduo de mineração como aditivo na produção de material cerâmico tem crescido entre os pesquisadores nos últimos anos. A indústria cerâmica está constantemente buscando a ampliação do mercado para o setor e tentando aperfeiçoar a qualidade dos produtos e aumentar a variedade de aplicações. A tecnologia de obtenção de cerâmica de revestimento que usa resíduos de mineração é um mercado ainda pouco explorado. Neste cenário, o objetivo do presente estudo foi caracterizar o resíduo gerado a partir de mineração de esmeralda, bem como para avaliar seu potencial uso como matéria-prima fundente para a produção de revestimentos cerâmicos. Misturas cerâmicas foram preparadas a partir de matérias-primas caracterizadas por fluorescência de raios X e difração de raios X. Cinco composições foram preparadas utilizando índices de resíduos de esmeraldas de 0\%, 10\%, 20\%, 30\% e 40\%. As amostras foram preparadas por prensagem, sinterizadas em 1000, 1100 e $1200{ }^{\circ} \mathrm{C}$ e caracterizadas visando estabelecer sua composição mineralógica, absorção de água, retração linear e módulo de ruptura à flexão. Os resultados mostraram que o resíduo de esmeraldas estudado pode ser incorporado na massa de revestimento cerâmico até $20 \%$ em substituição ao feldspato sem comprometimento das propriedades do produto final.
\end{abstract}

Palavras-chave: resíduo de esmeraldas, revestimento cerâmico, reciclagem e meio ambiente.

\begin{abstract}
Companies involved in mining and beneficiation of emerald represent an important area of industrial development in Brazil, with a significant contribution to world production of this ore. As a result, large volumes of waste generated and emerald are constantly abandoned in the environment, contributing negatively to their preservation. On the other hand the interest in the use of mining waste as an additive in production of ceramic materials has grown among researchers in recent years. The ceramic industry is constantly seeking to expand the market for the sector and trying to improve product quality and increase the variety of applications. The technology of obtaining ceramic coating that uses waste from mining is still a largely unexplored market. Thus, the purpose of this study was to characterize the waste generated from mining emerald as well as to evaluate its potential use as raw material for production melting of ceramic tiles. Ceramic mixtures were prepared from raw materials characterized by X-ray fluorescence and X-ray diffraction. Five compositions were prepared using the waste codes of emeralds from 0\%, 10\%, 20\%, 30\% and 40\%. Samples were prepared by pressing, sintered at 1000, 1100 and $1200{ }^{\circ} \mathrm{C}$ and characterized to establish their mineralogical composition, water absorption, linear shrinkage and modulus of rupture. The results showed that the residue of emeralds studied can be embedded in the mass of ceramic tiles up to $20 \%$ in replacement of feldspar without compromising the end product properties.
\end{abstract}

Keywords: residue of emeralds, ceramic, recycling.

\section{INTRODUÇÃO}

Com a revolução industrial a partir do século XVIII as nações focaram seus esforços no desenvolvimento, de forma a consolidar suas bases tecnológicas e sociais, e com isso pouca ou nenhuma preocupação existiu na utilização dos recursos naturais, que eram abundantes, e a natureza aceitava passivamente todos os dejetos que eram gerados nas industriais e descartados sem nenhum controle no meio ambiente. A necessidade do crescimento econômico 
em curto prazo, mediante a utilização de novos processos produtivos e a exploração intensiva de energia e matériasprimas, cujas fontes eram tidas como ilimitadas. Este modelo gerou excedentes impressionantes de riqueza econômica, mas trouxe consigo grandes problemas sociais e ambientais, entre eles os resíduos [1]. Nos últimos anos tem ocorrido um crescente interesse na prevenção da poluição ambiental, minimização de resíduos e desenvolvimento sustentado, sobretudo no desenvolvimento de novos materiais. O setor mineral gera enormes quantidades de resíduos de diversos tipos e níveis de periculosidade [2], como por exemplo, a extração de beneficiamento de esmeraldas, que gera grandes quantidades de resíduos a base mica (biotita e flogopita) e feldspato (anortita). O descarte de resíduos, de um modo geral, ocasiona um impacto ambiental muito forte, o que tem justificado o esforço de pesquisa visando encontrar uma solução racional para este problema [2].

O estado da Bahia, no nordeste do Brasil, tem veios de esmeraldas e seus minerais associados (água-marinha, berilo, molibdênio, talco, etc.), cuja exploração data da década de 60 , incluindo diversos municípios com garimpo na serra da Carnaíba e do garimpo Garimpo de Socotó [1]. De maneira geral, essas jazidas são exploradas de maneira desordenada por cooperativas de garimpeiros que geralmente não utilizam estudos geológicos prévios, nem acompanhamento técnico específico por ocasião da extração do minério. Essa atividade tem produzido um grande passivo ambiental para a região, sem contar que não traz um retorno financeiro esperado. Com isso, os minerais não são aproveitados na sua totalidade e muito material com valor agregado é descartado nas encostas, criando enormes depósitos de resíduos, contribuindo para o aumento do dano ambiental [2]. A utilização destes resíduos em formulações cerâmicas pode ser uma alternativa técnica interessante, assim como contribui com a revitalização das áreas degradadas e melhoria do ambiente nas áreas de mineração [2]. No presente trabalho, pretende-se avaliar a potencialidade técnica de utilização de resíduo proveniente do beneficiamento de esmeraldas do garimpo na Serra da Carnaíba, município de Pindobaçu - Bahia, como matéria-prima alternativa na fabricação de cerâmica de revestimento, tomando por base a formulação cerâmica composta de argila, caulim e feldspato, por meio da substituição parcial ou total do feldspato pelo resíduo.

\section{MATERIAIS E MÉTODOS}

Foram utilizadas matérias-primas que compõem uma massa industrial para fabricação de revestimento cerâmico, composta por argila (AR), caulim (CA) e feldspato (FE), denominada "Mistura A" (MA), anteriormente estudada [3] e o resíduo da planta industrial de beneficiamento de esmeraldas, da mineração "Bom Jesus na Serra da Carnaíba", garimpo da Carnaíba, do município de Pindobaçu, BA [4]. O resíduo do beneficiamento de esmeraldas (RBE) após coletado foi seco em estufa a $110^{\circ} \mathrm{C}$ por $24 \mathrm{~h}$, moído em um moinho triturador centrífugo de porcelana durante $20 \mathrm{~min}$ e passado na peneira 325 mesh. Em seguida o resíduo foi caracterizado por fluorescência de raios $\mathrm{X}$ e difração de raios $\mathrm{X}$. Todas as formulações foram misturadas em proporções definidas e apresentadas na Tabela I, denominadas "Mistura B" (MB), "Mistura C" (MC), "Mistura D" (MD) e "Mistura E” (ME).

Tabela I - Composição das massas utilizadas. [Table I - Compositions of the pastes.]

\begin{tabular}{cccccc}
\hline Material & $M A$ & $\begin{array}{c}M B \\
\text { (\%, em peso })\end{array}$ & $M C$ & $M D$ & $M E$ \\
\hline Argila (ARG) & 30 & 30 & 30 & 30 & 30 \\
Caulim (CAU) & 30 & 30 & 30 & 30 & 30 \\
Feldspato (FEL) & 40 & 30 & 20 & 10 & 0 \\
Resíduo (RBE) & 0 & 10 & 20 & 30 & 40 \\
\hline
\end{tabular}

As formulações cerâmicas foram preparadas de acordo com a seguinte rota de processamento: pesagem das matériasprimas, seguida de mistura em um misturador excêntrico. Com a massa das formulações semi-secas (umidade $\pm 7 \%$ ) foram prensados uniaxialmente 20 (vinte) corpos-de-prova de cada formulação (MA, MB, MC, MD e ME). Utilizou-se uma prensa com capacidade de $76 \mathrm{MPa}$, com pressão final $31 \mathrm{MPa}$. Os corpos-de-prova com dimensões 60 x 20 x $6 \mathrm{~mm}$ obtidos foram identificados, pesados e medidos. Em seguida, foram colocados em uma estufa elétrica a $110^{\circ} \mathrm{C}$, na qual permaneceram durante $24 \mathrm{~h}$ para remoção da umidade. Com 5 corpos-de-prova de cada mistura secos a $110{ }^{\circ} \mathrm{C}$ foram determinadas as seguintes características: cor Munsell após secagem (para estimativa após queima), retração linear de secagem, e tensão de ruptura à flexão. Os demais corposde-prova também secos foram queimados em forno elétrico até $1000{ }^{\circ} \mathrm{C}, 1100{ }^{\circ} \mathrm{C}$ e $1200{ }^{\circ} \mathrm{C}$, permanecendo $30 \mathrm{~min}$ na temperatura máxima. A velocidade de aquecimento do forno foi de $10{ }^{\circ} \mathrm{C} / \mathrm{min}$. Após o patamar isotérmico, o forno foi desligado e os corpos de provas foram resfriados dentro do próprio forno. Com estes corpos-de-prova foram determinadas as seguintes características: cor Munsell após a queima, perda ao fogo, retração linear após a queima, absorção de água, porosidade aparente, massa específica aparente e tensão de ruptura à flexão.

\section{RESULTADOS E DISCUSSÃO}

A Tabela II contém os resultados da análise química das matérias-primas. O resíduo da extração de esmeraldas é constituído predominantemente por sílica e alumina com teores elevados dos óxido de silício $(52,3 \%)$, de alumínio $(15,4 \%)$, e considerável teor de ferro $(5,4 \%)$. Parte do teor de óxido de ferro é originada do uso de equipamentos de corte durante a extração do minério, e pode influenciar na cor de queima do material. Os óxidos de magnésio $(10,3 \%)$, de potássio $(5,7 \%)$, de sódio $(1,8 \%)$ e de cálcio $(3,7 \%)$, totalizando $21,5 \%$ de óxidos fundentes, deverão contribuir para diminuir a quantidade de poros devido à formação de fase vítrea em temperaturas elevadas. Em contrapartida, o 
Tabela II - Composição química das matérias-primas. [Table II - Chemical composition of the raw materials.]

\begin{tabular}{ccccc}
\hline & RBE & ARG & CAU & FEL \\
\multicolumn{5}{c}{ \% em peso } \\
\hline $\mathrm{SiO}_{2}$ & 52,3 & 67,8 & 66,6 & 65,8 \\
$\mathrm{Al}_{2} \mathrm{O}_{3}$ & 15,4 & 24,0 & 29,6 & 17,5 \\
$\mathrm{MgO}$ & 10,3 & 0,9 & 0,1 & - \\
$\mathrm{K}_{2} \mathrm{O}$ & 5,7 & 2,8 & 0,8 & 12,0 \\
$\mathrm{Fe}_{2} \mathrm{O}_{3}$ & 5,4 & 2,4 & 0,7 & 0,5 \\
$\mathrm{CaO}$ & 3,7 & 0,1 & 0,1 & 0,1 \\
$\mathrm{P}_{2} \mathrm{O}_{5}$ & 1,9 & 0,2 & 0,1 & - \\
$\mathrm{Na}_{2} \mathrm{O}$ & 1,8 & 0,1 & 0,1 & 3,2 \\
$\mathrm{TiO}_{2}$ & - & 1,6 & 1,7 & - \\
$\mathrm{Outros}$ & 3,4 & 0,1 & 0,2 & 0,9 \\
\hline
\end{tabular}

RBE: Resíduo de esmeralda; ARG: Argila; CAU: Caulim; FEL: Feldspato
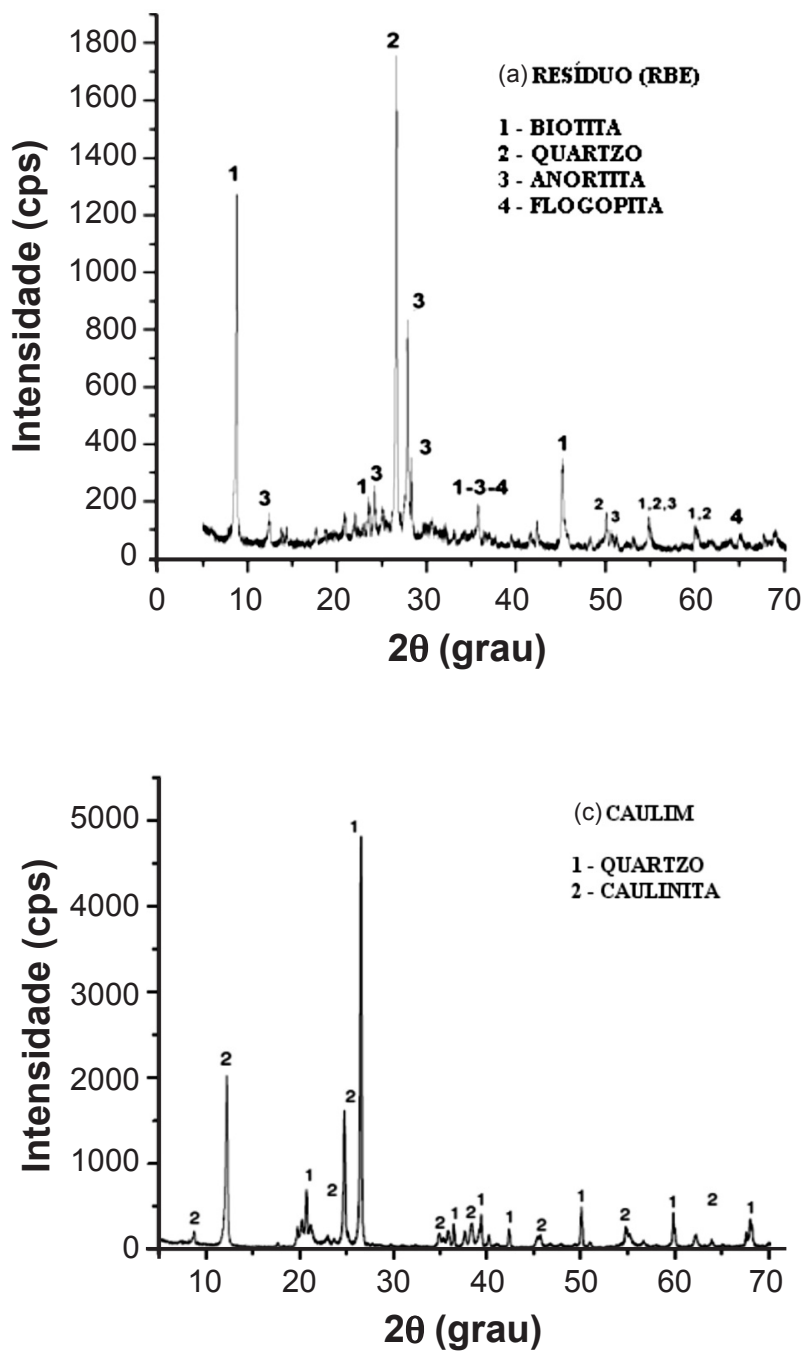

Figura 1: Difratogramas de raios $\mathrm{X}$ das matérias-primas. [Figure 1: X-ray diffraction patterns of the raw materials.] total de óxidos fundentes do feldspato é $15,3 \%$. Este fato é a principal motivação do interesse do estudo da incorporação do resíduo de esmeraldas na massa para a fabricação de revestimento cerâmico como matéria-prima alternativa na substituição do feldspato. As análises químicas do caulim e da argila apresentam uma composição química típica de um material pouco fundente e de possível queima clara, além de possui o caulim um teor maior de $\mathrm{Al}_{2} \mathrm{O}_{3}$ em relação às demais matérias-primas constituintes da massa.

A Fig. 1 apresenta o resultado da análise mineralógica das matérias-primas obtido por difração de raios X. Observase a presença no RBE, Fig. 1a, das fases micas (biotita e flogopita), feldspato (anortita) e quartzo, comprovando a existência dos minérios encontrados nas lavras de esmeraldas da Bahia e dos óxidos de cálcio, de sódio e de magnésio mostrados na análise química. A anortita $\left[\mathrm{Ca}\left(\mathrm{Al}_{2} \mathrm{Si}_{2} \mathrm{O}_{8}\right)\right]$ e o quartzo $\left(\mathrm{SiO}_{2}\right)$ comprovam sua presença nos óxidos determinados na análise química (Tabela II) por meio de seus componentes. As micas biotita $\left[\mathrm{K}(\mathrm{Mg}, \mathrm{Fe})_{3}(\mathrm{Al}, \mathrm{Fe})\right.$ $\left.\mathrm{Si}_{3} \mathrm{O}_{10}(\mathrm{OH}, \mathrm{F})_{2}\right]$ e flogopita $\left[\mathrm{KMg}_{3}\left(\mathrm{AlSi}_{3} \mathrm{O}_{10}\right)(\mathrm{OH})_{2}\right]$, que
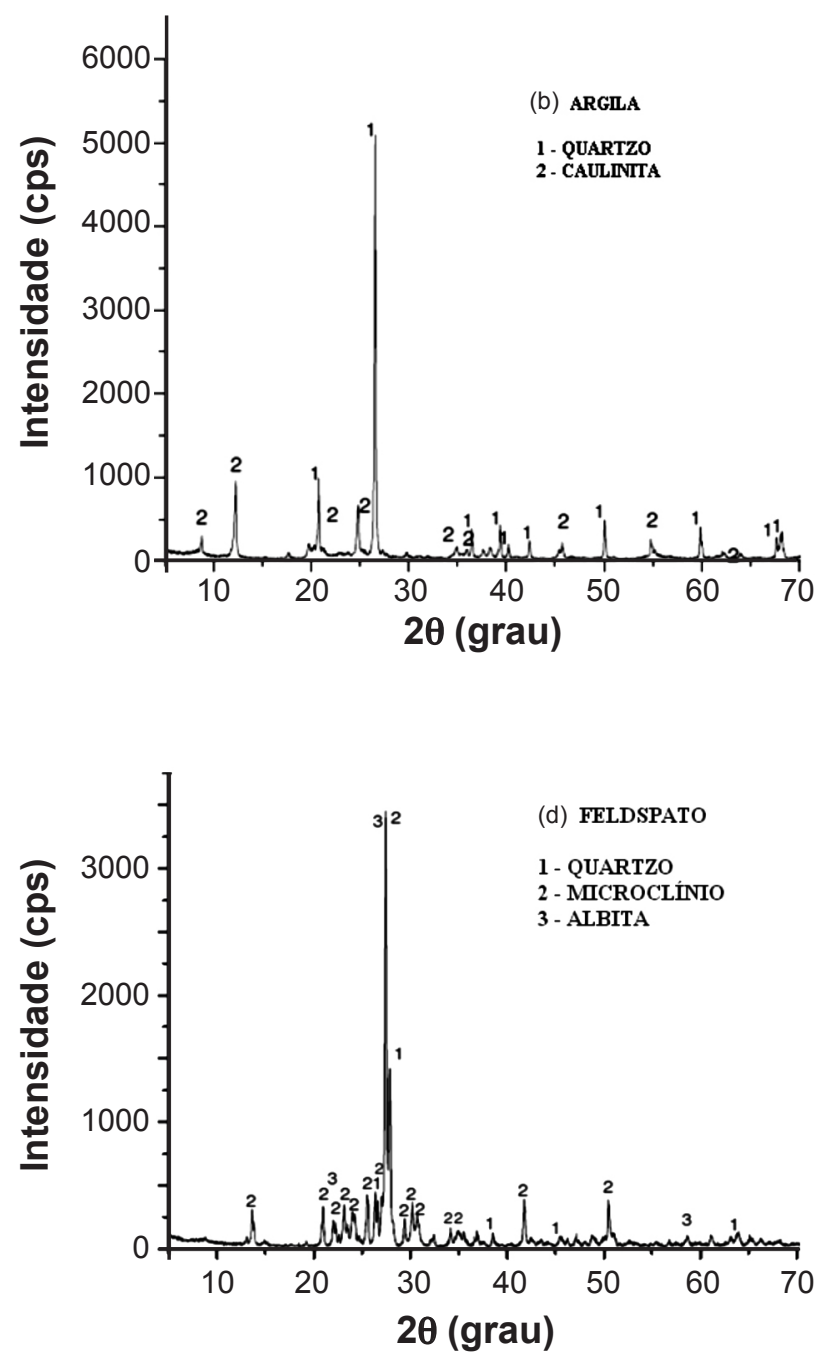
podem atuar como fundentes em temperaturas maiores de sinterização, ocorrem pela intrusão de pegmatito berilífero em rochas ultrabásicas que desenvolve em seu contato um leito filitoso composto de uma mica intermediária entre biotita e flogopita, no qual estão dispersas as esmeraldas. A Fig. 1b aponta que a argila em estudo é formada por apenas duas fases, quartzo e caulinita, comprovado pelo alto teor de $\mathrm{SiO}_{2}$ e de $\mathrm{Al}_{2} \mathrm{O}_{3}$ respectivamente, Tabela II. Com essa composição a argila apresenta potencial para ser utilizada na composição de revestimentos cerâmicos de qualidade. As fases identificadas nas amostras de caulim (Fig. 1c) e de feldspato (Fig. 1d) confirmam as características dessas amostras.

A Fig. 2 apresenta os resultados das análises
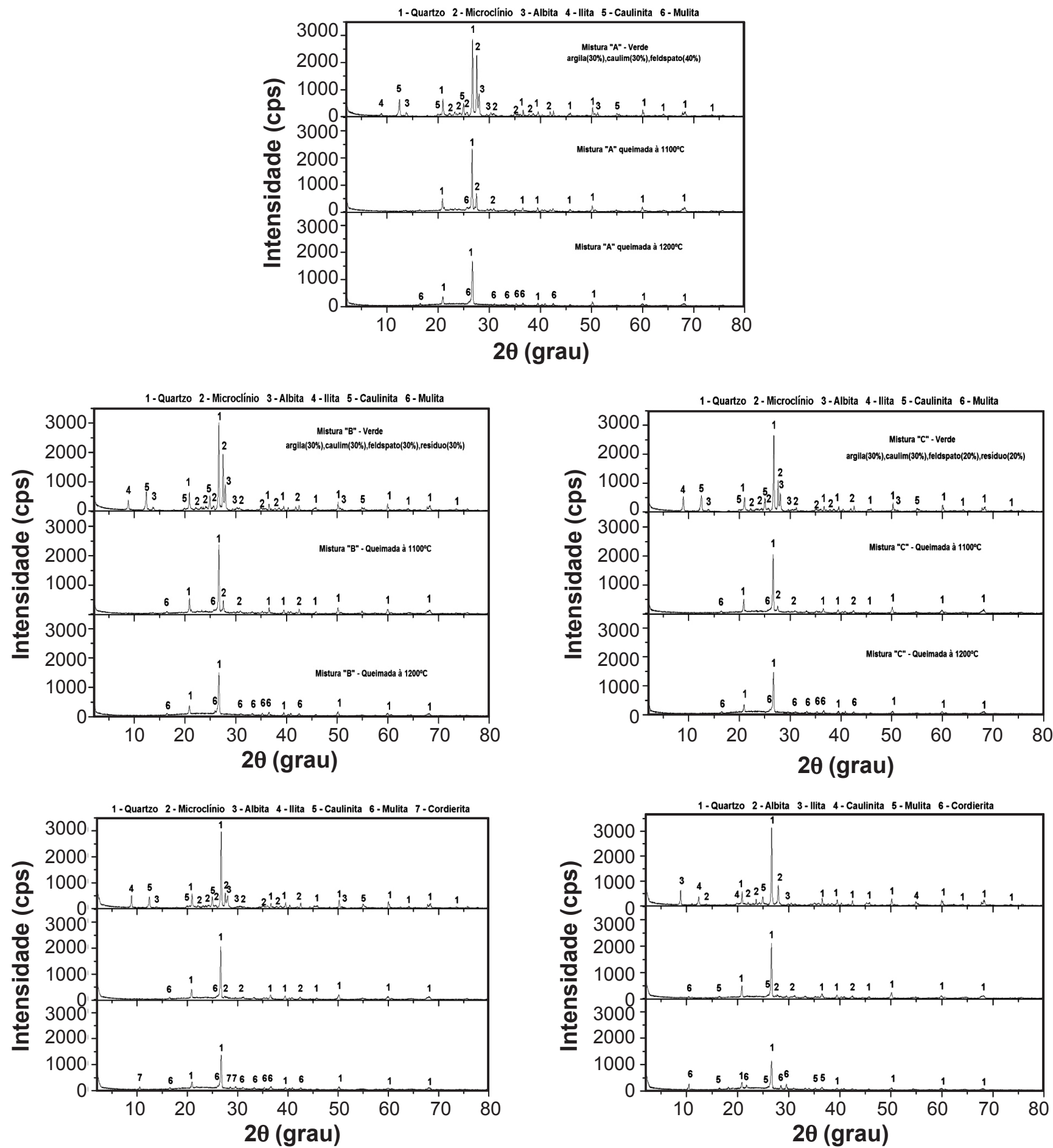

Figura 2: Difratogramas de raios X das composições com evolução térmica.

[Figure 2: X-ray diffraction patterns of compositions with thermal evolution.] 
mineralógicas das formulações em três condições: amostras a verde $\left(110{ }^{\circ} \mathrm{C}\right)$, amostras queimadas a $1100{ }^{\circ} \mathrm{C}$, e amostras queimadas a $1200{ }^{\circ} \mathrm{C}$. Em todas as formulações surge, a partir de $1100{ }^{\circ} \mathrm{C}$, uma nova fase que é a mulita $\left(3 \mathrm{Al}_{2} \mathrm{O}_{3} \cdot 2 \mathrm{SiO}_{2}\right)$. Esta fase é formada a partir dos espinélio e aluminossilicato amorfo, originado da argila e do caulim devido à caulinita, com formação entre 1050 e $1250{ }^{\circ} \mathrm{C}$. A presença da mulita em todas as formulações com resíduo comprova que ocorreu uma contribuição do resíduo no aumento da formação da quantidade de mulita e de fase vítrea. A formação de mulita normalmente melhora a resistência mecânica do material cerâmico. Após a queima das formulações algumas fases cristalinas (ilita e caulinita) foram dissolvidas e/ou transformadas em outra fase (mulita). Comparando a Fig. 1a com a Fig. 2 nota-se que as fases anortita e flogopita presentes no resíduo não foram detectadas nas formulações antes da etapa de queima, mesmo na formulação com adição de $40 \%$ do resíduo, comprovando que durante o processo de queima houve reação do resíduo de esmeralda com os demais componentes da formulação cerâmica.

A Tabela III apresenta a cor Munsell após secagem $\left(110^{\circ} \mathrm{C}\right)$ e após queima em três temperaturas. A adição do resíduo não influenciou na cor do material antes da queima, permanecendo a cor marrom claro em todas as formulações desenvolvidas. Na queima a $1000{ }^{\circ} \mathrm{C}$ a cor também não foi influenciada com a adição do resíduo, na qual a cor rosa claro foi exclusiva. Entretanto, a $1100{ }^{\circ} \mathrm{C}$ e $1200{ }^{\circ} \mathrm{C}$ o material mudou a cor característica, passando de rosa claro para marrom claro e marrom, e marrom acinzentado para marrom esverdeado. Nestes casos, a mudança da cor devese às reações e mudanças de fases que ocorrem no interior do material, tanto em relação à adição do resíduo, quanto ao aumento da temperatura. Destaca-se que o elevado teor de óxido de ferro no resíduo é responsável pela alteração na coloração da amostra, sendo compatível com a coloração avermelhada.

A Tabela IV apresenta o resultado do comportamento da retração linear e da perda de massa ao fogo das formulações estudadas. A menor retração ficou por conta das formulações MA e MB na menor temperatura, ressaltando assim o efeito de fundente do resíduo de esmeralda. Com o aumento da temperatura nota-se um aumento da retração na $\mathrm{MB}$ e MC. As formulações MB e MC queimadas a $1200{ }^{\circ} \mathrm{C}$ apresentaram percentuais de retração menores que o da formulação MA. É importante notar que na temperatura de queima de $1200{ }^{\circ} \mathrm{C}$ há uma redução drástica da retração com o aumento do percentual do resíduo partindo de $10 \%$ na formulação MA até 3,2\% nas formulações MD e ME com

Tabela III - Cor Munsell das composições antes e depois da queima.

[Table III - Munsell compositions before and after firing.]

\begin{tabular}{ccccc}
\hline \multirow{2}{*}{ Formulação } & & \multicolumn{2}{c}{ Temperatura $\left({ }^{\circ} \mathrm{C}\right)$} & \\
& $110{ }^{\circ} \mathrm{C}$ & $1000{ }^{\circ} \mathrm{C}$ & $1100{ }^{\circ} \mathrm{C}$ & $1200{ }^{\circ} \mathrm{C}$ \\
\hline \multirow{2}{*}{ MA } & $7,5 Y R 8 / 2$ & $5 Y R 8 / 4$ & $2,5 Y R 7 / 4$ & $10 Y R 5 / 2$ \\
& Marrom claro & Rosa claro & Rosa claro & Marrom acinzentado \\
MB & $7,5 Y R 8 / 2$ & $5 Y R 8 / 4$ & $2,5 Y R 7 / 4$ & $10 Y R 5 / 2$ \\
& Marrom claro & Rosa claro & Rosa claro & Marrom acinzentado \\
MC & $7,5 Y R 7 / 2$ & $5 Y R 8 / 4$ & $2,5 Y R 6 / 4$ & 10 YR4/2 \\
& Marrom claro & Rosa claro & Marrom claro & Marrom acinzentado \\
MD & $7,5 Y R 7 / 2$ & $2,5 Y R 7 / 4$ & $5 Y R 6 / 4$ & $10 Y R 4 / 2$ \\
& Marrom claro & Rosa claro & Marrom claro & Marrom acinzentado \\
ME & $7,5 Y R 7 / 2$ & $2,5 Y R 7 / 4$ & $5 Y R 5 / 4$ & $2,5 Y R 4 / 2$ \\
& Marrom claro & Rosa claro & Marrom & Marrom Esverdeado \\
\hline
\end{tabular}

Tabela IV - Retração linear e perda de massa das composições.

[Table IV - Linear shrinkage and mass loss of the compositions.]

\begin{tabular}{ccccccc}
\hline & \multicolumn{2}{c}{$1000{ }^{\circ} \mathrm{C}_{\mathrm{PF}}$} & \multicolumn{2}{c}{$1100{ }^{\circ} \mathrm{C}_{\mathrm{PF}}$} & \multicolumn{2}{c}{$1200{ }^{\circ} \mathrm{C}$} \\
Formulações & $\begin{array}{c}\mathrm{RL} \\
(\%)\end{array}$ & $(\%)$ & $\begin{array}{c}\mathrm{RL} \\
(\%)\end{array}$ & $\begin{array}{c}\mathrm{RL} \\
(\%)\end{array}$ & $\begin{array}{c}\mathrm{PF} \\
(\%)\end{array}$ \\
\hline MA & $0,0 \pm 0,1$ & $4,1 \pm 0,1$ & $3,0 \pm 0,1$ & $4,2 \pm 0,1$ & $10,0 \pm 0,1$ & $4,3 \pm 0,1$ \\
MB & $0,0 \pm 0,1$ & $4,4 \pm 0,0$ & $4,6 \pm 0,2$ & $4,4 \pm 0,1$ & $9,7 \pm 0,0$ & $4,5 \pm 0,1$ \\
MC & $0,5 \pm 0,1$ & $4,7 \pm 0,0$ & $6,2 \pm 0,2$ & $4,7 \pm 0,0$ & $6,3 \pm 0,2$ & $4,7 \pm 0,1$ \\
MD & $0,8 \pm 0,0$ & $4,9 \pm 0,1$ & $8,1 \pm 0,1$ & $5,0 \pm 0,1$ & $3,2 \pm 0,1$ & $4,9 \pm 0,1$ \\
ME & $1,2 \pm 0,1$ & $4,9 \pm 0,1$ & $8,2 \pm 0,1$ & $5,3 \pm 0,1$ & $3,2 \pm 0,1$ & $5,3 \pm 0,1$ \\
\hline
\end{tabular}


Tabela V - Absorção de água e resistência a flexão das composições.

[Table $V$ - Water absorption and flexural strength of the compositions.]

\begin{tabular}{|c|c|c|c|c|c|c|}
\hline \multirow[b]{2}{*}{ Formulações } & \multicolumn{2}{|c|}{$1000{ }^{\circ} \mathrm{C}$} & \multicolumn{2}{|c|}{$1100^{\circ} \mathrm{C}$} & \multicolumn{2}{|c|}{$1200{ }^{\circ} \mathrm{C}$} \\
\hline & $\begin{array}{l}\text { AA } \\
(\%)\end{array}$ & $\begin{array}{c}\text { TRF } \\
(\mathrm{MPa})\end{array}$ & $\begin{array}{l}\text { AA } \\
(\%)\end{array}$ & $\begin{array}{c}\text { TRF } \\
(\mathrm{MPa})\end{array}$ & $\begin{array}{l}\text { AA } \\
(\%)\end{array}$ & $\begin{array}{c}\text { TRF } \\
(\mathrm{MPa})\end{array}$ \\
\hline MA & $18,6 \pm 0,1$ & $22,1 \pm 3,2$ & $12,5 \pm 0,1$ & $16,9 \pm 1,9$ & $0,0 \pm 0,1$ & $49,7 \pm 5,04$ \\
\hline MB & $18,1 \pm 0,0$ & $37,1 \pm 4,5$ & $9,9 \pm 0,2$ & $25,1 \pm 1,4$ & $0,1 \pm 0,1$ & $62,6 \pm 7,17$ \\
\hline $\mathrm{MC}$ & $17,6 \pm 0,1$ & $36,5 \pm 1,9$ & $6,5 \pm 0,0$ & $31,2 \pm 3,1$ & $0,1 \pm 0,1$ & $38,2 \pm 3,04$ \\
\hline MD & $16,6 \pm 0,1$ & $68,8 \pm 8,5$ & $3,8 \pm 0,1$ & $32,2 \pm 2,7$ & $8,2 \pm 0,1$ & $20,7 \pm 1,27$ \\
\hline ME & $16,1 \pm 0,2$ & $86,8 \pm 1,8$ & $3,4 \pm 0,1$ & $32,0 \pm 1,6$ & $9,7 \pm 0,1$ & $21,2 \pm 1,89$ \\
\hline
\end{tabular}

maior percentual de resíduo, sendo que nesta formulação foi substituído todo o feldspato pelo resíduo. É possível que esse comportamento se deva à grande formação de fase líquida que, com o aumento do resíduo e conseqüente aumento dos poros, e esse líquido, com menor viscosidade tenha ocupado muitos daqueles poros. Também se pode considerar que a decomposição da caulinita nas formulações gera partículas muito reativas com alto poder de sinterização. Numa outra análise, a sinterização estaria acontecendo em temperatura inferior àquela da massa padrão ou com menor teor de resíduo, o que comprovaria a redução da temperatura de sinterização e maior produtividade, devido à redução de energia envolvida no processo. Com relação à perda de massa ao fogo o resíduo e a temperatura pouco influenciaram nas formulações estudadas, ocorrendo um pequeno aumento da perda de massa com o aumento do teor de resíduo.

Nas temperaturas de queima de $1000{ }^{\circ} \mathrm{C}$ e $1100{ }^{\circ} \mathrm{C}$ o aumento do teor de resíduo e a redução do teor de feldspato provocam um aumento na retração linear. A $1000{ }^{\circ} \mathrm{C}$ este aumento é bem discreto, sendo mais acentuado para a $1100{ }^{\circ} \mathrm{C}$. Nas formulações MA, MB e MC o aumento na temperatura de queima provoca aumento na retração, entretanto, para as formulações MD e ME o comportamento é invertido quando se compara a temperatura de queima de $1100^{\circ} \mathrm{C}$ com $1200{ }^{\circ} \mathrm{C}$. A $1200{ }^{\circ} \mathrm{C}$ o aumento do teor de resíduo provoca uma redução na retração linear, indicando assim que houve formação de fase líquida em grande quantidade na temperatura de $1200{ }^{\circ} \mathrm{C}$. A $1200{ }^{\circ} \mathrm{C}$ tem-se uma grande quantidade de fase líquida formada, que reage com o óxido de ferro proveniente da argila e do próprio resíduo, gerando uma expansão por geração de gases que impede a grande retração linear. Sabe-se que as formulações cerâmicas com elevados teores de óxido de ferro, apresentam problemas de deformação e trincas acima de $1150{ }^{\circ} \mathrm{C}$; entretanto, a presença de grande quantidade de fase líquida no caso das formulações estudadas evitou a deformação das amostras e o surgimento de trincas, o que deve ser considerado como uma característica positiva, uma vez que permite a fabricação de componentes cerâmicos com elevado teor de ferro sem deformação e surgimento de trincas. A Tabela $\mathrm{V}$ apresenta $\mathrm{o}$ resultado do comportamento da absorção de água e da tensão de ruptura a flexão das formulações estudadas. Analisando os valores de absorção de água e comparando-os com os parâmetros da norma ABNT 13818-1997 observa-se que as formulações MA, MB e MC, queimadas a $1200{ }^{\circ} \mathrm{C}$, se enquadram no "Grupo BIa" dos revestimentos cerâmicos. As formulações $\operatorname{MD}\left(1100^{\circ} \mathrm{C}\right)$ e $\mathrm{ME}\left(1100^{\circ} \mathrm{C}\right)$ se enquadram no "Grupo BIIa" (semi-grês). Nestas condições, a incorporação do resíduo de esmeraldas atende a diversas aplicações na fabricação de cerâmica para revestimento quanto à absorção de água e resistência mecânica. Um fato interessante observado no comportamento da absorção de água a 1200 ${ }^{\circ} \mathrm{C}$ foi nas formulações MD e ME, as quais apresentaram elevada absorção de água (maior que 8\%) e menor retração linear $(3,2 \%)$, fato este provocado, provavelmente, por um excesso de formação de fase vítrea devido à composição do resíduo, conforme descrito anteriormente.

\section{CONCLUSÕES}

É possível a substituição de até $20 \%$ do feldspato pelo resíduo de mineração proveniente da extração de esmeralda na massa para fabricação de cerâmica de revestimento, composta de argila (30\%), caulim (30\%) e feldspato (40\%). De acordo com as propriedades tecnológicas, os valores encontrados nas formulações propostas estão de acordo com a massa padrão de referência. Assim, o resíduo de esmeraldas que é jogado aleatoriamente no entorno das mineradoras instaladas na Serra da Carnaíba, BA, há mais de trinta anos, causando transtornos para os habitantes do local sem um estudo qualquer desses prejuízos, pode ser reciclado agregando valor como matéria-prima alternativa para a indústria cerâmica. Recomenda-se, portanto, o uso de tal resíduo nos moldes apresentados no presente trabalho, como matéria-prima fundente na fabricação de cerâmica de revestimento.

\section{AGRADECIMENTOS}

Ao CNPq e à CAPES pelo apoio financeiro.

\section{REFERÊNCIAS}

[1] R. F. Cavalcante, "Estudo do potencial de utilização do resíduo da extração de esmeraldas na fabricação de cerâmica de revestimento", Diss. Mestrado, Universidade Federal do Rio Grande do Norte, Natal, RN (2009).

[2] M. L. Varela, F. L. Formiga, R. P. S. Dutra, R. M. 
Nascimento, C. A. Paskocimas, Cerâmica 55, 334 (2009) 209-215.

[3] J. F. Brito, "Produção de grês-porcelanato a partir de matérias-primas do estado da Bahia", Diss. Mestrado, Universidade Federal do Rio Grande do Norte, Natal, RN
(2009).

[4] R. W. S. Silva, D. M. Moreira, "Esmeralda de carnaíba Bahia, Série arquivos abertos", 25, CBPM, Salvador, BA (2006).

(Rec. 16/03/2011, Ac. 20/07/2011) 